\title{
Cytological Changes Related to Brucella canis Variants Uptake in vitro
}

\author{
Igbo N. Egwu and Warren C. Eveland*
}

State University of New York at Buffalo, Department of Medical Technology, SUNYAB Clinical Center, Building AA - Room 107, 462 Grider Street, Buffalo, NY 14215, U.S.A.

\begin{abstract}
In this study, evidence for in vitro uptake, invasion, and cytopathogonomic effects of normal and variant strains of $B$. canis on tissue culture, is presented. B. canis L-phase were penicillin-induced and these microorganisms produced revertants on penicillin-free media: Tissue culture (LLC-MK 2$)$ cells were divided into different normal and variant-infected groups (I-IV), including controls. Bright-field and electron microscopic observations indicated uptake of all the strains and recognizable host cell damage (CPE) to varying degrees. At $72 \mathrm{~h}$ after infection, the extent of damage by L-phase was the least $(55.5 \%$ CPE). The L-phase-derived revertants resulted in $80 \%$ damage; this approximates the adverse effect of normal $B$. canis (85\%). In addition to these gross changes, various structural abnormalities, including pyknosis, nuclear disorganization, vacuolation, and karyorrhexis, were apparent. The implications of these findings and the indirect role of the L-phase in brucellosis due to $B$. canis are discussed.
\end{abstract}

\section{Introduction}

The ability of some organisms to initiate disease process depends to a great extent on attachment and eventual penetration of the host tissue surface. Tissue culture studies on other brucellae indicate different degrees of virulence. This fact has been demonstrated in chick embryo fibroblasts (Holland and Pickett, 1956) and guinea pig or mouse monocytes (Braun et al., 1958; Holland and Pickett, 1958); HeLa Cells (Shepard, 1959); Brucella abortus (Hatten et al., 1971). Brucella canis is the most recent member of the genus Brucella. In vivo pathogenesis of $B$. canis has been studied by several investigators including Carmichael and Kenny (1968) and Percy et al. (1972).

Since different strains of brucellae behave differently both in vivo and in vitro, studies of experimentally induced variants of the microorganisms are of interest in two respects: (1) They would provide experimental models for the examination of the selective effect of intracellular microenvironment. Studies of this kind could provide a basis for increasing knowledge and information about the host-parasite interaction of

\footnotetext{
*Professor Emeritus, The University of Michigan, Ann Arbor, MI., U.S.A.
} 
the normal and variant forms of $B$. canis. (2) The probable medical significance of $B$. canis has been stressed by Nicolleti et al. (1967), Morisset and Spink (1969), and Swenson et al. (1972).

We could find no report on in vitro studies involving either $B$. canis or its variants. The present study, therefore, concerns in vitro induction of $L$-phase and $L$-phase-derived revertants of $B$. canis, and the comparative effects of these variants on tissue culture.

\section{Materials and Methods}

\section{Bacterial and L-Pbase Variants}

The stock B. canis (strain RM 666) was originally obtained from Dr. L. Carmichael through Dr. D.H. Percy (University of Western Ontario, Canada). The bacteria were grown and maintained as described previously (Percy et al., 1972).

\section{L-Pbase Variants}

The $L$-phase variants used in infection experiments were induced with penicillin, using modified methods of Roux and Sassine (1971). The resulting variants were filtered through $0.45 \mu \mathrm{m}$ and $0.22 \mu \mathrm{m}$ Millipore filters (Millipore Corporation, Bedford, Massachusetts), respectively. Viable organisms, designated as filterable L-phase reproductive units ( $\mathrm{LPH}$ ), were thus obtained. These were subsequently propagated and maintained on antibiotic-free-L-variant media (LVM) (Egwu, 1973): 2.0\% dehydrated brucella broth (wt/vol) (Pfizer Diagnostics, New York); $2.9 \%$ NIH thioglycollate; 0.25 $M$ sucrose; $0.24 \% \mathrm{MgCl} \cdot 6 \mathrm{H}_{2} \mathrm{O}$. No reversion of organisms to bacteria occurred in artificial media prior to use.

\section{Revertant Bacteria}

Bacterial forms resulting from the early passages of penicillin-induced L-phase (unstable variants onto antibiotic-free media were maintained on brucella media as revertant stock cultures. Such revertants have been shown to exhibit different acrylamide gel electrophoretic patterns from those of parental bacteria (J. Schalles, 1976, personal communication).

\section{Tissue Culture Metbods}

Monkey kidney cells (LLC-MK2) obtained from Grand Island Biol., N.Y. (GIBCO) were used for this study. The cells were grown and maintained with medium 199 (M199) supplemented with $1 \%$ agamma-globulin horse serum (GIBCO). Penicillin (100 units $/ \mathrm{ml}$ ) and streptomycin $100 \mu \mathrm{g} / \mathrm{ml}$ (PS) were added in order to discourage extracellular growth of organisms. The cells were trypsinized $(0.25 \%)$, harvested at $1200 \mathrm{~g}$ and resuspended in M199 to contain about $10^{5}$ cells $/ \mathrm{ml}$. The suspension of cells was dispensed into suitable containers - bottles, roller/Leighton tubes, and incubated at $37^{\circ} \mathrm{C}$ under $5 \% \mathrm{CO}_{2}$ tension until monolayers were produced.

\section{Experimental Design and Infection}

The experiments were divided into three groups: Group I consisted of tissue culture cells infected with parental bacteria (PAR). In Group II, host cells were infected with 
revertant organisms (REV), while Group III comprised cells infected with L-phase or cell wall-defective variants (LPH). Group IV (MXD) cells received mixed strains. Appropriate controls of uninoculated tissue culture cells were set up. Tissue culture cells to be infected were grown on cover slips and replicates of those intended for electron microscopic studies were grown in 100-ml prescription bottles. Monolayers in each experimental group were washed twice with antibiotic-free Hanks balanced salt solution (HBSS), pH 7.6. The host cells were then infected with $0.1 \mathrm{ml}$ at approximately $9 \times 10^{7}$ organisms $/ \mathrm{ml}$ of washed parental or revertant bacteria suspended in phosphate-buffered saline (PBS, pH 7.6). For experiments involving infection with L-phase variants, $0.1 \mathrm{ml}$ standardized suspension (absorbance 0.75 at $260 \mathrm{~nm}$ ) was inoculated into each tube. The inocula into the cells grown in prescription bottles were increased fourfold. A 6-h adsorbance period in $\mathrm{M} 199$ containing penicillin $\mathrm{G}(100 \mathrm{U} / \mathrm{ml})$ to discourage possible reversion to bacteria, was employed.

Infected monolayers were washed several times with antibiotic-PBS, $\mathrm{pH} 7.6$, and reincubated in $\mathrm{M} 199$ with antibiotic at $37^{\circ} \mathrm{C}$ without medium change until the termination of each group of experiments. Uninoculated (control) monolayers were washed and reincubated under similar conditions. At appropriate intervals $(0,6,24$, and $72 \mathrm{~h})$, infected and corresponding control monolayers were withdrawn for further studies.

Light Microscopy: A modified May-Grünwald-Giemsa (MGG) staining (Merchant et al., 1960) was used. Briefly, monolayers were fixed in absolute ethyl alcohol for $5 \mathrm{~min}$, and stained with freshly diluted May-Grünwald stain for $20 \mathrm{~min}$, dehydrated in acetone, cleared in xylene, and mounted. Stained specimens were observed and photographed on Zeiss standard microscope (Zeiss, New York).

Indirect Immunofluorescent Antibody Test (IFA): Infected and uninoculated tissue culture cells on cover slips were rinsed in PBS ( $\mathrm{pH} 7.6$ ), overlaid with hyperimmune monkey anti-B. canis immunoglobulin G (IgG) prepared as described by Percy et al., 1972 ), for $30 \mathrm{~min}$ at $25^{\circ} \mathrm{C}$. They were washed for $10 \mathrm{~min}$ in PBS, then overlaid with dilute conjugate (goat-anti-monkey IgG, Cappel Labs., Inc. Dowington, PA), and incubated at $25^{\circ} \mathrm{C}$ for $30 \mathrm{~min}$. After rinsing in PBS, the preparations were mounted with buffered glycerine and examined with Zeiss fluorescence microscope equipped with Osram HBO 200 light source, BG-11 exciter filter, and OG4-GG4 barrier filter.

Electron Microscopy: Infected and control tissue culture cells representing appropriate experimental periods were scraped from the glass and washed in PBS, pH 7.6, by centrifugation. The pellet was fixed in $3 \%$ glutaraldehyde in $0.1 \mathrm{M}$ phosphate buffer ( $\mathrm{pH}$

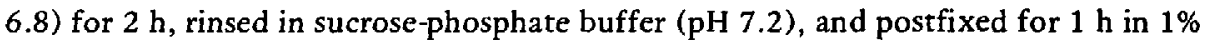
$\mathrm{OsO}_{4}$ in phosphate buffer. Samples were dehydrated through increasing concentrations of ethyl alcohol and transferred to propylene oxide and propylene-Epon mixture (Epon 812 epoxy resin) at $25^{\circ} \mathrm{C}$ for $2 \mathrm{~h}$ and $24 \mathrm{~h}$, respectively. The preparations were embedded in Epon and sections were cut on either LKB Ultratome or Reichert CMU2 ultramicrotome at about $70 \mathrm{~nm}$. The sections were stained with uranyl acetate and lead citrate (Frasca and Parks, 1965), and observed on AEI Corinth 275 electron microscope (AEI Scientific Apparatus, Elmsford, NY). 
Recovery of Intracellular Microorganisms: Recovery studies were performed on infected roller-tube cultures corresponding to various experimental intervals. The tubes were washed several times with sterile antibiotic-free PBS, pH 7.6. One milliliter of sterile distilled water was then added to each tube and allowed to stand for a few minutes after which the lysed host cells were vigorously shaken. One tenth of a milliliter of appropriately diluted samples from each tube was plated in replicates on solid media and incubated at $37^{\circ} \mathrm{C}$ for a maximum of 7 days to obtain viable counts. In order to recover the LPH organisms, both hypotonic and hypertonic diluents and media were used. Quantification of LPH isolates was unreliable because of the absence of discrete 'fried egg' colonies.

\section{Results}

\section{Invasion and Changes in Infected Host Cells}

As shown in Figure $1 \mathrm{~A}^{\prime}-\mathrm{C}$, the microbial agents used in this study invaded the host cells within $24 \mathrm{~h}$. Intravacuolar (brightfield) and transmission electron photomicrographic evidence (Fig. 2C, F) were used as criteria to determine intracellular localization. Additional evidence was obtained by light microscopy through intracellular organisms which stained less intensely. The identity of intracellular microorganisms was established by indirect IFA. Semiquantitative cytopathic effect (CPE) of the microorganisms on host cells is summarized in Table 1 which shows that gross damage at 72 h was $85 \%$ (Group I), 80\% (Group II), 55.5\% (Group III), and 70.5\% (Group IV).

Group I (PAR-Infected Host Cells): PAR organisms tended to localize in perinuclear vacuoles in the cytoplasm, although some bacteria were also present in the interstitial regions (Fig. 1A'). There was no evidence of direct nuclear invasion, but there were some recognizable changes attributable to the presence of the organisms. These changes included pyknosis and nuclear disorganization; multiple vacuoles in the invaded areas of the cytoplasm were observed at both light and electron microscope (EM) levels (Figs. 1A' and 2B).

Group II (REV-Infected Host Cells): In REV-infected cells, the pattern of localization of bacteria is similar to that of PAR-infected tissue cells. However, intravacuolar clusters of bacteria, in relation to the host nuclear region, were more striking (Fig. 1B).

Nuclear changes were similar to those observed in PAR-infected cells. However, cytoplasmic involvement was evidently more extensive. Extensive bacterial clumps were also observed at EM level (Fig. 2C). Vacuoles and cytopathic effect (CPE), apparently due to overwhelming organisms, were abundant. In some areas of the cytoplasm, EM studies also showed myelin-like structures (Fig. 2C).

Group III (LPH-Infected Cells): In contrast to PAR or REV-infected cells, LPHinfected cells, as shown by immonofluorescent studies, indicated that about $80 \%$ of the cells were associated with some LPH organisms shortly after inoculation. Suggestive karyorrhexis and ill-defined nuclear membranes (Fig. 2D) were evident $24 \mathrm{~h}$ after infection. Cytoplasmic changes observed included degeneration, destruction of many areas of the cells, and vacuolation. LPH organisms were present either as granules or 


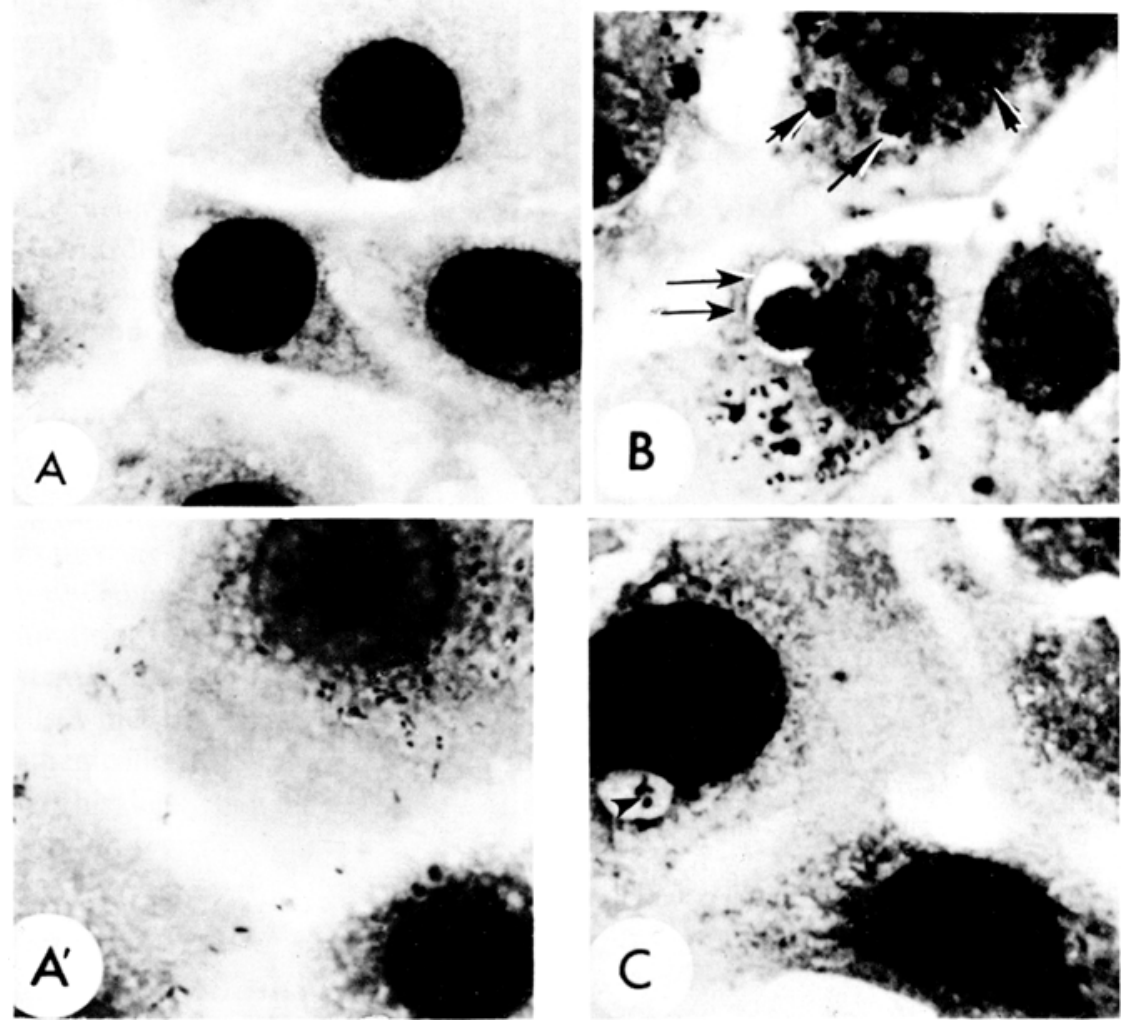

Fig. 1. A. Uninfected (control) LLC-MK 2 monkey kidney tissue culture monolayer (MayGrünwald Giemsa, MGG stain $\times 3200$ ). $A^{\prime}$. Tissue culture cells infected with parental $B$. canis. Note intracellular organisms (MGG stain, $x$ 3200). B. Host cells infected with revertant $B$. canis. Note multiple vacuoles gorged with bacteria arrows indicate large vacuoles impinging on host nuclear membrane, (MGG stain $\times 3200$ ). C. L-phase-infected host cells showing intravacuolar round bodies (arrow) (MGG stain $\times 3200$ )

Table 1. Semi-quantitative estimation of Gross CPE at 24, 48 , and $72 \mathrm{~h}$ after infection

\begin{tabular}{lccc}
\hline & \multicolumn{4}{c}{ Degree of damage (\%) } \\
& 24 & 48 & 72 \\
\hline & & & \\
I Proup & 35.5 & 72.5 & 85.0 \\
II Revertant (REV) & 30.5 & 70.5 & 80.0 \\
III L-Phase (LPH) & $<10.0$ & 30.5 & 55.5 \\
IV Mixed (MXD) & 20.0 & 45.5 & 70.5 \\
Control & 0 & 0 & 0 \\
\hline
\end{tabular}

a Based on the average number of cells damaged per 200 microscope fields on triplicate slides in each group 


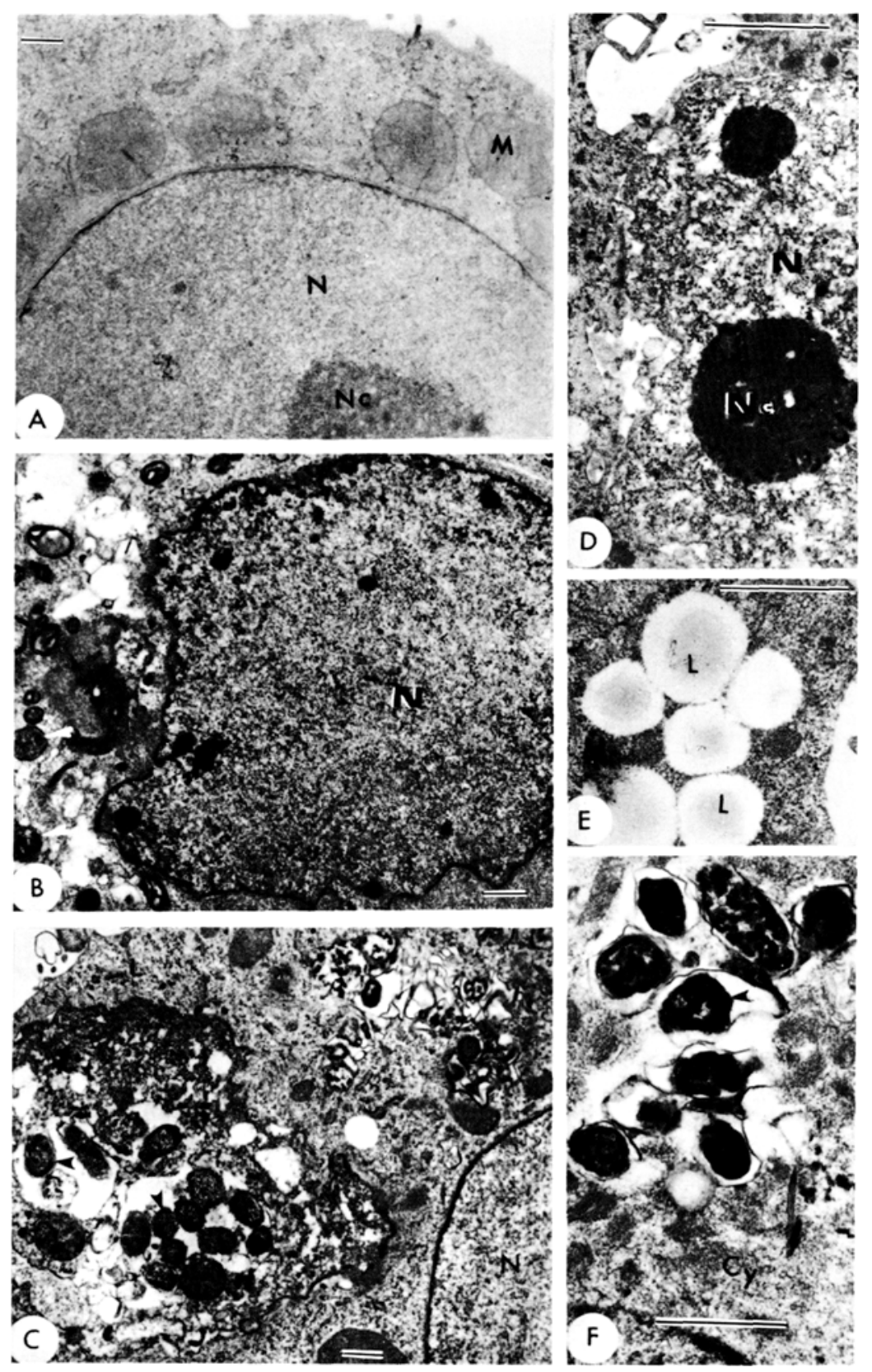

Fig. 2. Transmission electron micrographs of normal and infected tissue culture cells. A. Uninoculated (control) cells $(\mathrm{bar}-1 \mu \mathrm{m}), m=$ mitochondrium; $n=$ nucleus; $N c=$ nucleolus. B. Parent organism-infected tissue culture cells. Note intracellular bacterium in cross section (arrow). $N=$ nucleus $(\mathrm{bar}=\mathrm{l} \mu \mathrm{m})$. C. Host cells infected with revertant organisms. Note numerous in tracellular $(F)$ bacteria (arrow) (bar $=1 \mu \mathrm{m})$. D,E. Tissue culture cells infected with cell wall defective variants, LPH (L-phase) organisms. Note lipid droplets $(L)(b a r=1 \mu \mathrm{m})$ 
superficial aggregates as shown by IFA; EM studies also revealed numerous lipid droplets (Fig. 2E).

Group IV (MXD): In parallel experiments in which mixed forms (MXD) were inoculated, adverse cytopathogenic changes were also observed although some of the results were inconsistent.

Control tissue culture cells did not produce any of the pathogonomic changes observed in test cultures (Fig. 1A). The nuclei were oval or spherical and stained normally. No abnormal changes were observed in EM preparations (Fig. 2A).

\section{Recovery of Intracellular Organisms}

PAR and REV Organisms: Some disappointing results were obtained from isolation experiments in which infected host cells were incubated in M199-containing antibiotics mixture. At $24 \mathrm{~h}$ after infection, only REV organisms produced significant recovery counts of $1.4 \times 10^{6}$ organisms/ml after the seventh day of continuous incubation. Prior to this time, counts were negligible. PAR-infected host cells yielded consistently low viable counts for the same period. Curiously, even with REV-infected host cells, which would otherwise produce good growth within $24 \mathrm{~h}$, the growth of isolates on penicillin-free agar did not occur until after 4 days of incubation. It is speculated that this delay may be due to a probable suppressive effect of the PS mixture. The behavior of PAR bacteria appeared comparable to that of the REV organisms.

\section{Discussion}

The poor recovery of PAR and REV organisms after $48 \mathrm{~h}$ appeared to be consistent with the general decrease in intracellular activities of the microorganisms even in PSfree media. The decline, therefore, may represent a decline in growth curve, possible microbial death, intracellular conversion of PAR, or reconversion of REV to the $L$ phase. This explanation appears to be supported by the isolation of some L-phase organisms from REV-infected host cells. Observations on the LPH-infected cells were more difficult to quantify because the L-phase did not produce discrete colonies.

All the brucella forms were found to be intracellularly localized within $24 \mathrm{~h}$ after infection and were also capable of provoking host-parasite interactions. Host cell damage, as determined by cytopathic effect (CPE), resulted from the presence of these forms in the tissue culture cells. The host-parasite interactions and microbial growth were adversely affected by the presence of penicillin-streptomycin mixture in the extracellular fluid. This is in agreement with other reports (Richardson and Holt, 1962; Hatten and Sulkin, 1968). On the basis of the observed behavior of REV bacteria, intracellularly and in cell-free cultures, we propose that the term parental be reserved only for the normal bacteria unexposed to L-phase inducer, in this case, penicillin. The REV bacteria tended to grow faster and formed mucoid colonies on solid media. The latter property may reflect a possible presence of surface material which makes the organisms tenacious. Similar substances in other bacterial species have been associated with microbial attachment to host membranes (Ellen and Gibbons, 1974). If this holds for the REV bacteria, such surface properties would enhance adherence during infection; consequently, more REV bacteria would attach to the membrane. 
It is conceivable that these cells would be intimately associated with each other, even intracellularly. This may be the possible mechanism underlying the observed pattern of perinuclear vacuoles gorged with clusters of REV organisms. In contrast, PAR- or LPHinfected cells, while showing multiple vacuoles within the cytoplasm, show no distinct pattern.

Many investigators have shown that the L-phase of certain bacteria may produce toxins and various other metabolites which may be harmful to the host (Guze, 1968). Conversely, it has been demonstrated that other bacterial L-phase variants may not be directly involved in the disease process, but may only be a protective phase of the organism's life process. We have examined these possibilities in this study which permitted observations at the cellular level. The results indicate that the L-phase of $B$. canis and their revertants, under the reported experimental conditions, cause demonstrable changes in host tissue culture cells. Moreover, the known indirect role of the L-phase in pathogenesis (via REV) is demonstrated in this study. However, more definitive work, in vivo, must be done to substantiate these observations.

Acknowledgments. The excellent technical comments and help of Dr. R, Gray and Mrs. Kay Brabec are appreciated. We also thank Mrs. Frances Peebles, Terry O'Leary, and Mrs. Mary Johnson. This investigation was partially supported by grants from the Society of the Sigma Xi, the Scientific Research Society of North America.

\section{References}

Braun, W., Pomales-Lebrón, A., Stinebring, W.R.: Interactions between mononuclear phagocytes and Brucella abortus strains of different virulence. Proc. Soc. Exp. Biol. Med. 97, 393-397 (1958)

Carmichael, L.E., Kenny, R.M.: Canine abortion caused by Brucella canis. J. Am. Vet. Med. Assoc. 152, 605-616 (1968)

Egwu, I.N.: New methods in the study of bacterial L-forms and Mycoplasma. Hlth. Lab. Sci. 10, 7-12 (1973)

Ellen, R.P., Gibbons, R.: Parameters affecting adherence and tissue tropisms of Streptococcus pyogenes. Infect. Immun. 9, 85-91 (1974)

Frasca, J.M., Parks, V.R.: A routine technique for double-staining ultra-thin sections using uranyl and lead salts. J. Cell Biol. 25, 157-160 (1965)

Guze, L.B. (ed): Microbial protoplasts, spheroplasts and L-forms. Baltimore: Williams and Wilkins Co. 1968

Hatten, A., Sulkin, S.E.: Possible role of Brucella L-forms in pathogenesis of brucellosis. In Guze, L.B. (ed.): Microbial protoplasts, spheroplasts and L-forms. Baltimore: Williams and Wilkins Co. 1968

Hatten, B.A., Huang, S.T., Schulze, M.L., Sulkin, E.: Electron Microscopy of tissue culture cells infected with Brucella abortus. J. Bacteriol. 108, 535-544 (1971)

Holland, J.J., Pickett, M.J.: Intracellular behavior of brucella variants in chick embryo cells in tissue culture. Proced. Soc. Exp. Biol. Med. 93, 476-479 (1956)

Holland, J.J., Pickett, M.J. : A cellular basis in experimental Bracella infection. J. Exp. Med. 108, 343-360 (1958) 
Merchant, D.J., Kahn, R.H., Murphy, W.H.: Handbook of cell and organ culture p. 182. Minneapolis: Burgess Pub. Co. 1960

Morrisset, R., Spink, W.W.: Epidemic canine brucellosis due to a new species, Brucella canis. Lancet, 1969 II, 1000

Nicolleti, P.L., Quinn, B.R., Minor, P.W.: Canine to human transmission of brucellosis. N.Y. J. Med. 67, 2886-3002 (1967)

Percy, D.H., Egwu, I.N., Jonas, A.M.: Experimental Brucella canis infection in the monkey, Macaca arctoides. Can. J. Comp. Med 36, 221-225 (1972)

Richardson, M., Holt, J.: Synergistic action of streptomycin with other antibiotics on intracellular Brucella abortus in vitro. J. Bacteriol. 84, 638-646 (1962)

Roux, J., Sassine, J,: Etude D'une souche fixée de sphéroplastes (formes L) de Brucella melitensis. Am. Inst. Past. 120, 174 (1971)

Shepard, C.C.: Nonacid-fast bacteria and HeLa cells: their uptake and subsequent intracellular growth. J. Bacteriol. 77, 701-714 (1959)

Swenson, R.M., Carmichael, L.E., Cundy, K.R.: Human infection with Brucella canis. Ann. Int. Med. 76, 435-438 (1972) 